\title{
Evaluation of the Role of Simulation Training in Nuchal Translucency Measurement
}

\author{
Mahesh $^{1}$, Rithi Melissa D Silva ${ }^{2}$, Abhishek Menon ${ }^{3}$, Lulu Sherif ${ }^{4}$, Prajnha U P ${ }^{5}$ \\ ${ }^{1}$ Senior Resident, Department of Radio Diagnosis, 'Junior Resident, Department of Radio Diagnosis, ${ }^{3} J u n i o r$ Resident, \\ Department of Radio Diagnosis, ${ }^{4}$ Associate Professor, Department of Anaesthesiology, Father Muller Muller College and \\ Hospital , Mangalore, ${ }^{5} \mathrm{~K}$ S Hegde Institute of Medical Scienes, Deralakatte, Mangalore, India
}

Corresponding author: Mahesh, Senior Resident, Department of Radio Diagnosis, Father Muller Medical College and Hospital, Kankanady, Managaluru-575002, India

DOI: http://dx.doi.org/10.21276/ijcmsr.2019.4.2.11

How to cite this article: Mahesh, Rithi Melissa D Silva, Abhishek Menon, Lulu Sherif, Prajnha U P. Evaluation of the role of simulation training in nuchal translucency measurement. International Journal of Contemporary Medicine Surgery and Radiology. 2019;4(2):B47-B50.

\section{A B S T R A C T}

Introduction: Chromosomal aberrations are the most frequent and significant disorders, the forms of which vary widely. It is a wellestablished fact that ultrasound-based screening for chromosomal anomalies in the first trimester should include NT measurement. Study objective was to see the effect of simulation based ultrasonography training compared with conventional training only, on performance of first year radiology residents in nuchal translucency (NT) measurement.

Material and methods: This is a comparative study between two $1^{\text {st }}$ year radiology residents. The study is a single center, randomized observer-blind trial. One of the resident was trained in the conventional method. The other resident received simulation based ultrasonography training (for 2 week) in NT scan. Following the training modules, both the participants performed NT scan on 100 pregnant women using Philips Affinity 50 machine. Subsequently, those images was evaluated by a blinded experienced radiologist who scored them based on specific criteria.

Results: The results showed a distinct difference in the performance of the two study participants. The participant trained in simulation fared better with higher total mean score ( $p$ value 0.009). Statistically significant difference was found between certain evaluation criteria. Conclusion: Accurate NT measurement is a demanding process. Traditional ultrasound teaching is a time consuming process using human models, direct faculty time, and a dedicated ultrasound machine. Our study is one of the first to examine skills transfer after simulationbased ultrasound training. It demonstrates that, compared with conventional training only, simulation-based ultrasound training during residency has a better immediate impact. The study showed that the use of an ultrasound simulator is an effective instrument of learning for residents. It can have reaching impact if integrated into the teaching curriculum to supplement the conventional training.

Keywords: Nuchal Translucency, Simulation, Ultrasonography

\section{INTRODUCTION}

Chromosomal aberrations are the most frequent and significant disorders, the forms of which vary widely from the clinically silent to the ones with fatal outcome (trisomy 13,18). As the consequences for the affected families are grave, diagnosis of chromosomal anomalies has been the main aim of prenatal screening. ${ }^{1}$

It is a well-established fact that ultrasound-based screening for chromosomal anomalies in the first trimester should include NT measurement. ${ }^{2,3}$ The sensitivity of this method for detecting Downs syndrome is $70-80 \%$ with a $5 \%$ rate of false positive findings. ${ }^{1}$ The efficiency of the screening is further enhanced by use of biochemical markers, like free beta or totalhuman chorionic gonadotropin (hCG) and pregnancy-associated plasma protein-A (PAPP-A) which raises the sensitivity to $90 \% .^{1,4}$

Most experts recommend that NT should be measured between 11 and $13+6$ weeks, corresponding to a CRL measurement of between 45 and $84 \mathrm{~mm}$. This is because NT as a screening test performs optimally and fetal size allows diagnosis of major fetal abnormalities, thus providing women who are carrying an affected fetus with the option of option of an early termination of pregnancy. ${ }^{5}$

Optimal NT implementation requires suitable equipment as well as well trainedsonologists. ${ }^{6}$ The use of uultrasonography use is highly operator-dependent. ${ }^{7}$ The lack of sufficient operator skills can lead to diagnostic errors that may compromise patient safety due to unnecessary tests or interventions. ${ }^{8}$ However, ultrasound training is associated with long learning curves and is therefore timeconsuming and requires extensive teaching resources. ${ }^{9.10}$ Consequently, some residents may never acquire the basic skills and knowledge needed for independent practice. ${ }^{11}$

The use of simulators as educational tools for medical procedures is spreading rapidly. Recent studies of usage of ultrasound simulators have shown, that the confidence of using sonography and in image interpretation skills there were no difference in groups who have been trained using 
patient or those who have been trained using simulators. ${ }^{12-14}$ Simulation-based medical education (SBME) has been suggested as an adjunct to early ultrasonography training ${ }^{11,15-20}$ but there is limited evidence of skill transfer from simulation to performance. ${ }^{21}$

Study objective was to see the effect of simulation based ultrasonography training compared with conventional training only, on performance of first year radiology residents in nuchal translucency (NT) measurement.

\section{MATERIAL AND METHODS}

This is a comparative study between two $1^{\text {st }}$ year radiology residents. The primary investigator is responsible for the selection of participants randomly using lottery chit method. The study is a single center, randomized observer-blind trial. The exclusion criteria are: any formal ultrasound training in NT scan and prior virtual-reality simulation experience. Participation is voluntary, and informed consent will be obtained from both participants. One of the resident (Candidate 1) was trained in the conventional method as followed in our department by observation of NT scans by staff radiologists for a period of 2 weeks. The other resident (Candidate 2) received simulation based ultrasonography training (for 2 week) in NT scan in the simulation Centre at Father Muller Medical college and Hospital in the presence of an instructor. The simulation sessions was of 1hour duration spread over 2 weeks. The simulation system used was Vimedix (CAE Healthcare) Simulation system which consists of a torso model mannequin, a TAS probe and a monitor. Both participants received a standardized, introductory 30minute lecture on the use of ultrasound, NT basics and measurement techniques. Following the training modules, both the participants performed NT scan on 100 pregnant women using Philips Affinity 50 machine.

The scan images and measurements obtained by both participants were saved in the ultrasound machine. If more than one measurement meeting all the criteria was obtained, the maximum one was recorded.

Subsequently, those images was evaluated by a blinded experienced radiologist who scored them based on specific criteria.

The fulfillment of the following criteria was assessed during evaluation and will be rated as follows:

1. Appropriate magnification to include only the fetal head and upper thorax in the whole screen. $(0=$ absent $1=$ present $)$.

2. Identification of the amniotic membrane separately from the fetus. $(0=$ correct $1=$ incorrect $)$.

3. The presence of the echogenic tip of the nose, $(0=$ not seen 1 = partially seen 2 =optimally seen).

4. rectangular shape of the palate anteriorly, $0=$ not seen $1=$ partially seen 2 =optimally seen).

5. the translucent diencephalon in the center. $(0=$ not seen $1=$ partially seen $2=$ optimally seen).

6. Proper placement of calipers (on-on) to measure NT as the maximum distance between the nuchal membrane and the edge of the soft tissue overlying the cervical spine. $(0=$ improper 1 =proper $)$

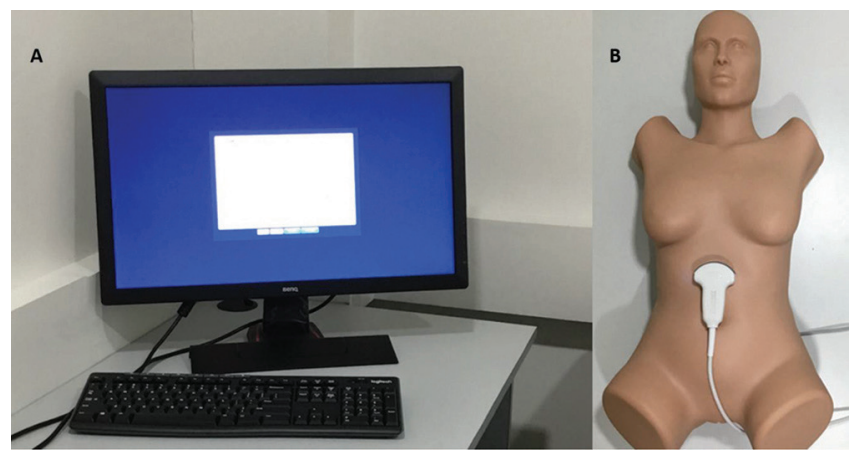

Figure-1: The Vimedix simulation monitor and Mannequin

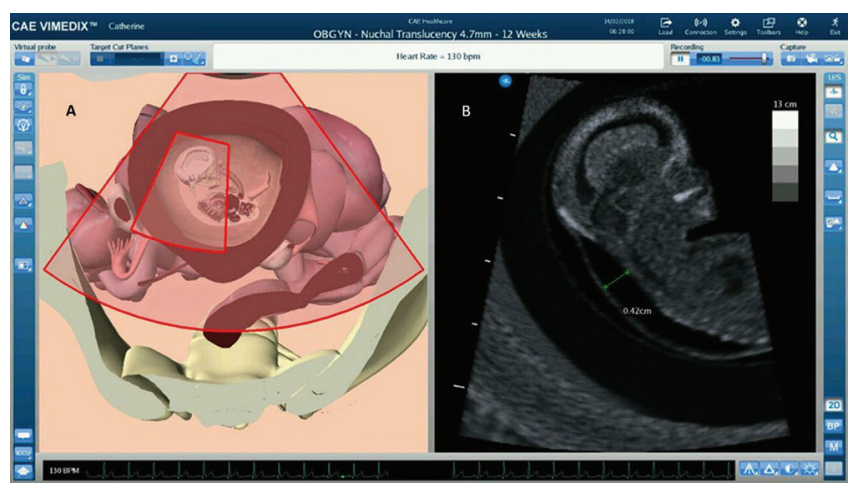

Figure-2: Representative simulation image of normal NT scan in Vimedix

The data was analyzed using Mean and Wisconsin signed rank tests.

\section{RESULTS}

A total of 2 participants were tested in this study who performed $100 \mathrm{NT}$ scans each on the same pregnant women. The resident trained with simulation is denoted as candidate 1 and the resident trained in conventional method is denoted as candidate 2 in the tables 1,2.

The results showed a distinct difference in the performance of the two study participants. The participant trained in simulation fared better with higher total mean score ( $p$ value 0.009). Statistically significant difference was found between certain evaluation criteria like visualization of Diencephalon, hard palate and nasal bone.

\section{DISCUSSION}

Simulation based medical education (SBME) has proven to be effective in improving knowledge, skill and behaviour of health care professionals. Simulation has been effectively used to teach procedural skills, surgical skills and crises resource management. There is evidence of simulation being used to train individuals, teams, environments, technical factors, system factors and patient factors..$^{6-8}$

The use of simulation teaching learning tool is known to impart learning among students through Experiential learning with reflection on action. Majority of the existing literature is from the western world who have been using simulation as a modality to teach, assess, for research. The Medical Council of India (MCI) has proposed its new Competency Based Medical Education (CBME) with 


\begin{tabular}{|l|l|l|l|l|l|l|}
\hline Participant & Mean & STD & $\begin{array}{l}\text { WilcoxonSigned } \\
\text { Rank Test }(z \\
\text { value) }\end{array}$ & $25^{\text {th }}$ & $50^{\text {th }}$ & $75^{\text {th }}$ \\
\hline $\begin{array}{l}\underbrace{}_{\text {(Simulation) }} \\
2\end{array}$ & $\mathbf{8 . 9}$ & 2.2 & 2.609 & 7.00 & 8.50 & 11.25 \\
\hline (conventional) & $\mathbf{4 . 4}$ & 2.6 & & 2.000 & 4.0 & 7.0
\end{tabular}

Table1: Overall mean scores of the participant 1(trained in simulation) and participant 2(trained in conventional method). Pvalue0.09

\begin{tabular}{|c|c|c|c|c|c|}
\hline PARAMETER & Median & $25^{\text {th }}$ CENTILE & $\begin{array}{l}7^{\text {th }} \\
\text { CENTILE }\end{array}$ & $\begin{array}{l}\text { Wilcoxonsign } \\
\text { ed rank test } z \\
\text { value }\end{array}$ & p value \\
\hline $\begin{array}{l}\text { DIENCEPHALON } \\
1 \\
2\end{array}$ & $\begin{array}{l}1.00 \\
0.00\end{array}$ & $\begin{array}{l}0.75 \\
0.00\end{array}$ & $\begin{array}{l}2.00 \\
1.00\end{array}$ & -2.305 & 0.02 \\
\hline $\begin{array}{l}\text { HARD PALATE } \\
1 \\
2\end{array}$ & $\begin{array}{l}1.50 \\
0.50\end{array}$ & $\begin{array}{l}1.00 \\
0.00\end{array}$ & $\begin{array}{l}2.00 \\
1.00\end{array}$ & -2.428 & 0.01 \\
\hline $\begin{array}{l}\text { NASAL BONE } \\
1 \\
2\end{array}$ & $\begin{array}{l}1.00 \\
0.00\end{array}$ & $\begin{array}{l}1.00 \\
0.00\end{array}$ & $\begin{array}{l}2.00 \\
1.00\end{array}$ & -2.126 & 0.03 \\
\hline $\begin{array}{l}\text { CORRECT NT } \\
\text { IDENTIFICATION } \\
1 \\
2\end{array}$ & $\begin{array}{l}2.00 \\
1.00\end{array}$ & $\begin{array}{l}1.00 \\
0.75\end{array}$ & $\begin{array}{l}2.00 \\
2.00\end{array}$ & -1.897 & 0.05 \\
\hline $\begin{array}{l}\text { CALIPER } \\
\text { PLACEMENT } \\
1 \\
2\end{array}$ & $\begin{array}{l}2.00 \\
2.00\end{array}$ & $\begin{array}{l}2.00 \\
1.00\end{array}$ & $\begin{array}{l}2.00 \\
2.00\end{array}$ & -1.633 & 0.10 \\
\hline $\begin{array}{l}\text { IMAGE ZOOM } \\
1 \\
2\end{array}$ & $\begin{array}{l}2.00 \\
0.00\end{array}$ & $\begin{array}{l}0.75 \\
0.00\end{array}$ & $\begin{array}{l}2.00 \\
1.25\end{array}$ & -1.732 & 0.08 \\
\hline
\end{tabular}

Table-2: Mean scores of individual parameters between the two participants; $1=$ Candidate $12=$ Candidate 2

Attitude, ethics and communication (AETCOM) module from August 2019 for all undergraduate and postgraduate curriculum. For CBME to be implemented skills and simulation centres will play a vital role in achieving mastery level.

Accurate NT measurement is a demanding process requiring sufficient time, clinical practice and experience. Traditional ultrasound teaching is a time consuming process using human models, direct faculty time, and a dedicated ultrasound machine. Our study one of the first to examine skills transfer after simulation-based ultrasound training. The limitations of the study is that it compares the performance of only two individuals rather than catering to a wider spectra. ${ }^{9-11}$

\section{CONCLUSION}

Our study demonstrates that, compared with conventional training only, simulation-based ultrasound training during residency has a better immediate impact. The study showed that the use of an ultrasound simulator is an effective instrument of learning for residents. It can have reaching impact if integrated into the teaching curriculum to supplement the conventional training.

\section{REFERENCES}

1. Entezami M. Ultrasound diagnosis of fetal anomalies. 1st ed. Stuttgart: ThiemeVerlag; 2004.

2. Nicolaides KH, Azar G, Byrne D, Mansur C, Marks K. Fetal nuchal translucency: ultrasound screening for chromosomal defects in first trimester of pregnancy. BMJ; 1992; 304(1): 867-869.

3. Nicolaides KH, Snijders RJ, Gosden CM, Berry C, Campbell S. Ultrasonographically detectable markers of fetal chromosomal abnormalities. Lancet 1992; 340 (3): 704-707.

4. Kagan KO, Wright D, Baker A, Sahota D, Nicolaides KH. Screening for trisomy 21 by maternal age, fetal nuchal translucency thickness, free beta-human chorionic gonadotropin and pregnancy-associated plasma protein-A. Ultrasound ObstetGynecol 2008; 31 
(5): 618-624.

5. Nicolaides KH. Screening for fetal aneuploidies at 11 to 13 weeks. PrenatDiagn 2011; 31 (1): 7-15.

6. Salomon LJ, Alfirevic Z, Bilardo CM, Chalouhi GE, Ghi T, Kagan KO, Lau TK, PapageorghiouAT, RaineFenning NJ, Stirnemann J, Suresh S, Tabor A, TimorTritsch IE, Toi A, Yeo G. ISUOG Practice Guidelines: performance of first-trimester fetal ultrasound scan. Ultrasound Obstet Gynecol 2013; 41 (3): 102-113.

7. European Federation of Societies for Ultrasound in Medicine. Minimum training requirements for the practice of Medical Ultrasound in Europe. Ultraschall Med 2010; 31 (1): 426-427.

8. Moore CL, Copel JA. Point-of-care ultrasonography. N Engl J Med 2011; 24 (2): 749-757.

9. Jang TB, Ruggeri W, Dyne P, Kaji AH. The Learning curve of resident physicians using emergency ultrasonography for cholelithiasis and cholecystitis. AcadEmerg Med 2010; 17 (4): 1247-1252.

10. Jang TB, Jack Casey R, Dyne P, Kaji A. The learning curve of resident physicians using emergency ultrasonography for obstructive uropathy. AcadEmerg Med 2010; 17 (6): 1024-1027.

11. Tolsgaard MG, Rasmussen MB, Tappert C, Sundler M, Sorensen JL, Ottesen B, Ringsted C, Tabor A. Which factors are associated with trainees' confidence in performing obstetric and gynecological ultrasound examinations? Ultrasound ObstetGynecol 2014; 43 (3): 444-451

12. Bentley S, Mudan G, Strother C, Wong N. Are Live Ultrasound Models Replaceable? Traditional vs. Simulated Education Module for FAST Exam. West J Emerg Med. 2015; 16 (1): 818-822.

13. Damewood S, Jeanmonod D, CadiganB.Comparison of a multimedia simulator to a human model for teaching FAST exam image interpretation and image acquisition. AcadEmerg Med. 2011; 18 (5):413-9.

14. Burden C, Preshaw J, White P, Draycott TJ, Grant S, Fox R. Usability of virtual-reality simulation training in obstetric ultrasonography: a prospective cohort study. Ultrasound ObstetGynecol 2013; 42 (1): 213-217.

15. Salvesen KA, Lees C, Tutschek B. Basic European ultrasound training in obstetrics ${ }^{\circ}$ and gynecology: where are we and where do we go from here? Ultrasound ObstetGynecol 2010; 36 (5): 525-529.

16. Tutschek B, Tercanli S, Chantraine F. Teaching and learning normal gynecological ultrasonography using simple virtual reality objects: a proposal for a standardized approach. Ultrasound ObstetGynecol 2012; 39 (4): 595-596.

17. Tutschek B, Pilu G. Virtual reality ultrasound imaging of the normal and abnormal fetal central nervous system. Ultrasound ObstetGynecol 2009; 34 (3): 259-267.

18. Heer IM, Middendorf K, Muller-Egloff S, Dugas M, Strauss A. Ultrasound training: " the virtual patient. Ultrasound ObstetGynecol 2004; 24 (1): 440-444.

19. MaulH,Scharf A,Baier P,Wustemann M, G* unter $H H$, Gebauer G, Sohn C. Ultrasound simulators: experience with the SonoTrainer and comparative review of other training systems. Ultrasound ObstetGynecol 2004; 24 (6): 581-585
20. Madsen ME, Konge L, Nørgaard LN, Tabor A, Ringsted C, Klemmensen AK, Ottesen B, Tolsgaard MG. Assessment of performance measures and learning curves for use of a virtual-reality ultrasound simulator in transvaginal ultrasound examination. Ultrasound ObstetGynecol 2014; 44 (4): 693-699.

21. Blum T, Rieger A, Navab N, Friess H, Martignoni M. A review of computer-based simulators for ultrasound training. Simul Healthc 2013;8 (2):23-30.

\section{Source of Support: Nil; Conflict of Interest: None}

Submitted: 03-04-2019; Accepted: 25-04-2019; Published online: 19-05-2019 